\title{
AESTHETIC LITERACY: OBSERVABLE PHENOMENA AND PEDAGOGICAL APPLICATIONS FOR MOBILE LIFELONG LEARNING (MLLL)
}

\author{
MichaelSean Gallagher[mseangallagher@hufs.ac.kr], Hankuk.University of Foreign Studies, Seoul, Republic \\ of Korea, Pekka Ihanainen [pekka.ibanainen@baaga-belia.fi], HAAGA-HELIA University of Applies \\ Sciences, Helsinki, Finland
}

\begin{abstract}
This paper proposed a method for developing capacity for lifelong learning in open spaces, defined here as places without predefined learning structures or objectives, through the cultivation of aesthetic literacy. This discussion will be situated within fieldwork performed by the authors in Helsinki, Finland, and Tallinn, Estonia, in 2013. Based on the researchers' experience in the field of teacher education and workshops they have conducted on mobile learning, the empirical context for this discussion focuses on data generated from the research methods of participatory observation (ethnography), autoethnography, reflective concept analysis and artistic subjectivity. These methods and the data generated as a result collect to produce insight into how aesthetic literacy sits within the cross-section of open space, mobile learning, and lifelong learning,
\end{abstract}

Aesthetic literacy, appropriated and broadened from its original focus as capacity for "reading" or making meaning from artistic material (discussed in Gale, 2005 as the "living of lyrical moments"), is positioned in this paper as a means of making meaning in open spaces through alignment and attunement. This paper presents pragmatic methods for pedagogically cultivating learning in open spaces through a focus on aesthetic literacy. The pedagogical advantages of such an approach and its applicability to lifelong learning, particularly lifelong learning activated through mobile technology (or mobile lifelong learning-mLLL), follows along with recommendations for further research. The applicability of such research is for teachers, learners, or researchers who are looking for methods for making use of open spaces for learning, or to cultivate learners who actively seek learning in the "rhythms of the everyday" (Lankshear \& Knobel, 2011).

The aim of the article is to produce fresh insights into the academic discussion about the nature of open space, mobile learning and lifelong learning as seem from the point of view of aesthetic literacy, insights we believe have distinct pedagogical advantages for mLLL.

Focal Area: Informal arenas of learning - learning opportunities in daily life and the workplace; Learning process design, teaching methodologies

Keywords: lifelong learning, mobile learning, mLLL, open learning, pedagogy, field activity

\section{Introduction: From Mobile Learning to Lifelong Learning}

Research has suggested the possible role of network technologies in lifelong learning (Koper \& Tattersall, 2004), and a shift in recent years from the role of the educational institution in providing those technologies compared with recent trends towards individual ownership and use of existing technologies (Kalz, 2014). It is in the utilization of mobile technology, personally 
owned rather than organizationally given, towards a particular learning orientation that we wish to focus this paper. We look to narrow our focus on lifelong learning supported by mobile technology, an adjusted version of mobile lifelong learning (mLLL) as defined by Seta et al (2014) as a combination of both mobile learning, "essentially an ensemble of didactic practices based on the use of mobile technologies", and lifelong learning, "a general vision of knowledge in the education society." The definition adopted in this paper acknowledges these didactic practices and suggests an appropriation of Kress and Pachler's (2007) notion of mobile learning as a "transformation of habitus", where the mobile in mobile learning is the transformation of space, including cognitive space, into learning space. As it relates to lifelong learning, this version of mLLL suggests that the pedagogical focus of lifelong learning is in fostering the capacity of the individual learner to generate meaning in open contexts, to transform this open space into learning space.

As such, if we view lifelong learning as an overarching activity, and mobile learning as a method for enacting that activity, we are left with defining the environment in which this activity takes place. For this, we turn to open space and look to broaden its current use.

\section{From Mobile and Lifelong Learning to Open Space}

Open space in this paper (and as introduced in Gallagher \& Ihanainen, 2014b) is space without a predefined form, space outside a course, resource, or learning structure. Open space can refer to urban, rural, suburban, or natural spaces; it can refer to physical, digital, or hybrid space of both (as is often the case with mobile learning in a physical context). It can refer to a walk down the street, a daily commute, a quiet meditation in the corner of a cafe or a lakeshore etc. A learner in this space must contend with the lack of a predefined learning objective, the lack of a predefined cache of learning materials, or even a full awareness of the learning potential in the space itself. Learners in this open space often respond to these "rhythms of the everyday" to create "everyday practices" (Lankshear \& Knobel, 2011), or methods of making meaning in these open contexts. These everyday practices help us make use of open space; they tend to be informal and can be individual or socialized methods for making meaning in uncertain environments. These environments tend to be mobile insomuch as they are not geographically predefined; there is no predefined space for learning. The technologies in which learning in the open is managed, engaged with, composed through, etc. tend to be both mobile technology and non-digital technologies (papers, pencils, notebooks, etc.).

As such, we believe a pedagogy in response to this open space is one that extends this idea of making learning visible to its earliest stages of alignment and attunement, collected in this paper under aesthetic literacy. We believe that making the process by which the learner transforms open space into learning space (Kress and Pachler's (2007) transformation of habitus) visible to the learner allows them to consciously reflect on these "everyday practices" of alignment and attunement, refine their capacity for aesthetic literacy, and replicate the process in all open environments. It is lifelong learning with or without predefined objectives, with or without a predefined process in place or a clear understanding of the ultimate knowledge outputs. It is learning that can be stimulated in the learner through conscious reflection on and iterations of process, a process aggregating everyday practices with specific learning practices and activities. In short, we believe the potential overlap between lifelong learning, mobile learning, and open space is significant, under-theorized, and potentially generative for pedagogy.

\section{Aesthetic Literacy}

As this paper suggests, this transformation and use of open space as learning space involves a sophisticated process of alignment, attunement, data collection, composition, and reflection (outlined in Gallagher \& Ihanainen, 2013, 2014a), a process repeated incessantly both consciously 
and subconsciously in response to newly identified knowledge gaps, new goals or motivations, or from sheer curiosity. We have encapsulated parts of this process into what we call aesthetic literacy, an ability to identify learning potential in everyday and open environments and to methodically enact a process of learning through them. Aesthetic literacy, appropriated and broadened from its specific artistic focus as a capacity for "reading" or making meaning from artistic (everyday) material (discussed in Gale (2005) as the "living of lyrical moments"), is positioned as a means of making meaning in open environments, or as a means of enacting lifelong learning in these open spaces.

What this paper suggests is that aesthetic literacy is much more than the capacity for communicating through or as a result of art; it is a capacity for transforming space into learning space as a result of a process of alignment and attunement. Learners align themselves to the possibility of learning in an open environment (a trust in their own capacities for finding learning material in their open, lived worlds), and then attune themselves to their specificities of their environment for learning (acknowledging that each location is a constructed, specific set of attributes- learning in a museum as opposed to the subway as opposed to an open field, etc.). What follows this aesthetic literacy is a more traditional learning practice: data collection, composition, and reflection.

In practice you can imagine walking along the city street among crowds of people and perceiving flows of movement, colour palettes, symphonies of odours and sounds etc., which form meanings to the learner; e.g. "a peace between people"- a question of the cultural, economic and political interaction of mankind. As described, this involves the utilization of aesthetic literacy. Aesthetic literacy develops in iterative loops of perceiving and acting. It includes identifying thinking, emotional intent and intentional orientation. Aesthetic literacy consists of continuous transitions, which are made visible via documentary collages that people create. In aesthetic literacy meaning making, action and encounters come true through beauty in empathy, respect and compassion. The beauty is a resonating state and readiness to perceive and act, which is simultaneously invigorating, sensitive and determinate. Aesthetic literacy can be developed and learned, and it is crystallized in the ability to align and attune.

The aesthetic literacy approach to learning is especially aligned with social constructivism (e.g. Wenger), connectivism (Siemens), and systemic psychology (e.g. Järvilehto, 2000). Aesthetic literacy activities like collaborative discussions, jointly implemented data collection, and sharing of artefacted collages are all knowledge constructions interacting with people's short-term and long-term communities. The cyborgic wearable technology is a natural part of aesthetic literacy. From a learning perspective, aesthetic literacy is the unity of the human-environment-technology continuum. In aesthetic literacy, learning is defined as a state of becoming mentally, physically, and perceptually sensitized, through alignment and attunement, to the environmental system in which the individual is resonating. This rationale is concurrent with the systemic psychology view of seeing learning as a process of widening and differentiation of the human-environment system.

\section{Alignment and attunement}

Alignment and attunement refer to how we as humans cope with environments and niches in which we are embedded. As a primary activity they are crucial survival skills and commonplace, but in more sophisticated instances, they will go beyond a routine of automatic perception and response. Alignment is connected with perceptual sensitivity, which means not only to perceive towards as is common, but backwards, onwards and by as well. Perceiving towards means that we align ourselves with perceptible matter like a sunrise and sunset. Perceiving backwards is in relation to earlier perceptual experiences, which is made visible in the present like seeing in the actual "vague" sunset all the strong and saturated colours that were present before. Perceiving 
onwards is related to being inside the actual perception like seeing in the sunrise a pace of the forthcoming day, a predictive perception of future possibility. Perceiving by refers to perception that is not fixed to some point or continuum, but to the periphery. It means a possibility to see "invisible" lines, forms etc. building quite new meanings and realisations for the perceiver. For instance looking by trees, fog and framing windows of the landscape in front of is possible to see brightening dynamics of horizontal, vertical and sagittal, which give a fruitful mental state to creative buzzing - and realize line thinking possibilities in aesthetic literacy. Aesthetic alignment is a unique collection of perceiving towards, backwards, onwards and by in an authentic situation of urban, rural, suburban and natural physical, digital or hybrid places.

Attunement is connected with activities oriented to the environment, which we refer to as behavioural rhetorics. The idea of behavioural rhetorics comes from Aristotle's rhetoric of logos, pathos and ethos (as discussed in Braet, 1992). Logos refers to spoken language and argumentation created and used when speaking. Pathos includes the emotions of both the speaker and the audience. Ethos is activity by which the speaker tries to persuade the audience. Aristotelian rhetoric is a persuasion skill and ability, and it is an aggregation of bodily, intellectual and emotional activity. When we speak about behavioural rhetorics as an element of aesthetic literacy and characterizing attunement type of orientation we refer to three kinds of active resonance. They are anticipatory emptiness, emotional openness and bodily vigilance, and they are related to Aristotelian logos, pathos and ethos. Behavioural rhetorics refer in the Aristotelian sense to persuasion of the met environment into an aesthetic attunement.

Anticipatory (Järvilehto et al, 2013) emptiness is an active cognitive state of preparedness to recognize significance in open environments. Anticipatory emptiness can be seen as an active silence or blank mind. An example of this can be understood when likened to urban flanerie, as learners meander through their open environments without a predetermined learning goal. "While the cityscape may be teeming with crowds and commerce, the flaneur opens his senses and paints his own picture of the city" (Dörk et al, 2011); flanerie, when positioned this way, is itself an act of anticipatory emptiness. By way of example, imagine walking in the old town of Bratislava and seeing statues and then suddenly, through an anticipatory emptiness, composing an understanding of historical events and beauty through those statues. In this positioning, anticipatory emptiness is a cognitive state for cultivation.

Emotional openness is closely connected with anticipatory emptiness. When you are cognitively anticipating meaning in an open environment, feelings are allowed to arise as such, thereby freeing the mind to craft meaning from dynamic environments. In the statue example above, one first might experience a feeling of amusement, sadness, gratitude, etc. This is then further perceived a historical or other lens, which can then be transformed to political and ideological statements to be said aloud, composed, or reflected upon. In order for this process to occur, emotional openness as a state of readiness is needed. Without this state of readiness, the mind is filled by "previous" thoughts and emotions which prevent you from seeing "differently." Without an anticipatory emptiness and emotional openness, the statues will only ever be seen as statues, not as a convergence of meaning across historical, aesthetic, and artistic planes.

Bodily vigilance is a part of anticipatory emptiness and emotional openness. It is an openness to physically move, change position and to seek new perspectives for aesthetically attuning and immersing oneself in one's actual niche. Bodily vigilance makes anticipatory emptiness and emotional openness possible, enlarges and deepens them while being simultaneously embedded in them. Bodily vigilance raises the importance of embodiment into sight, especially as embodied in a global and culturally spread out body in a mobile interactive reality (Farman, 2012, 2013). Bodily vigilance, anticipatory emptiness and emotional openness are interdependent, so they can only be fully separated in an analytical sense. As an aggregated whole, they function as 
behavioural rhetorics and are mechanisms for aligning and attuning oneself to the learning potential of open environments.

\section{Research Background \& Emergent Methodology}

The basis of this research is grounded in artistic practice, autoethnography, and fieldwork. Methodologically our approach roots itself in an ethnographic research paradigm, while still giving more emphasis to heuristics for creative discussion than defined research outcomes. The data collection (fieldwork) for meaning making with aesthetic literacy is organized via workshops, in which participants represent a sort of focus group (outlined in Gibbs, 1997), and researchers then induce observations and interpretations from those groups into reflective conceptual figures. Besides workshops, the researchers' own everyday participatory observations, modified from more systematic observation methods (such as those outlined in Atkinson \& Hammersley, 1994) are used to produce insights for phenomenon at hand. Researchers work like artesans to create artefacts such as video postcards to exemplify reflected and created concepts and explanations. To be specific, the key research method is autoethnography, which is described in detail immediately following the summary table presented as follows.

Table 1:

\begin{tabular}{|l|l|l|l|}
\hline Method & Theory Drawn On & $\begin{array}{l}\text { Data Collected or } \\
\text { Composed }\end{array}$ & Notes \\
\hline Field Activity & $\begin{array}{l}\text { Emerging from } \\
\text { qualitative research, } \\
\text { fieldwork remains at } \\
\text { the center of much } \\
\text { humanities and science } \\
\text { based practice } \\
\text { (outlined in Chang \& } \\
\text { Ooi, 2008). }\end{array}$ & $\begin{array}{l}\text { Audio, Video, Imagery, } \\
\text { GPS (\& other } \\
\text { metadata), Text (Field } \\
\text { Notes) }\end{array}$ & $\begin{array}{l}\text { In this approach, the } \\
\text { field activity is } \\
\text { discussed but not } \\
\text { overtly predefined, } \\
\text { allowing for } \\
\text { serendipitous and } \\
\text { intentional findings }\end{array}$ \\
\hline Autoethnography & $\begin{array}{l}\text { Both autobiographical } \\
\text { and ethnographic } \\
\text { crafting of space } \\
\text { (Phillips, 2011) }\end{array}$ & $\begin{array}{l}\text { Research questions, } \\
\text { focus or positioning for } \\
\text { further data collection, } \\
\text { reflective practices }\end{array}$ & $\begin{array}{l}\text { Observations of } \\
\text { community in which } \\
\text { researcher is a member } \\
\text { or a participant } \\
\text { foregrounds the } \\
\text { subjectiveness of open } \\
\text { learning. }\end{array}$ \\
\hline Narrative Inquiry & $\begin{array}{l}\text { Webster \& Mertova, } \\
2007\end{array}$ & $\begin{array}{l}\text { Multimodal artifacts } \\
\text { composed from data } \\
\text { collected in field }\end{array}$ & $\begin{array}{l}\text { Artifacts composed by } \\
\text { open learners from } \\
\text { their data present the } \\
\text { autoethnographic } \\
\text { narrative of the } \\
\text { experience }\end{array}$ \\
\hline
\end{tabular}

\section{Autoethnography and Open Space}

Emerging from, among other things, "the "crisis of confidence" inspired by postmodernism in the 1980s" in the social sciences (Ellis \& Bochner, 2000), autoethnography combines aspects of both autobiography and ethnography in that it is self-reflection and writing that explores the experience of the researcher within a particular environment in an attempt to connect that experience to broader cultural, social, political or other meanings. It is meant to be observational 
and reflexive simultaneously; it also does not purport to limit the lack of objectivity inherent to its structure. Autoethnography acknowledges and supports the tension of being both an insider (group member) and outsider (researching the group) in a social dynamic. In the method presented in this paper, the autoethnographer employs a particular gaze through a particular landscape, of which they are a member, employing a particular set of tools towards a particular constructed meaning (Saljo, 1999). Our focus in aesthetic library is on enacting the autoethnography of open space.

Autoethnographers, as reflexive practitioners, are reliant on the data collected in the open space as well as the notes, writings, or compositions composed as a result of that data. The data (or artifacts) collected or analyzed in this process, including the architecture of urban space (Phillips, 2011), are both collected and composed by the autoethnographer themselves. For example, a photograph taken with mobile technology of a particular urban landscape is framed, or interpreted, by the researcher. Video, aural, or textual data collected would be interpreted, or framed, in much the same way, maintaining an emphasis in autoethnography on narrative-based approaches for meaning-making and reflexivity in method (Ellis \& Bochner, 2000). The autoethnographer in open space would both compose the space and compose their understanding of that space simultaneously, reflexively iterating on methods and practices to do so. Or, autoethnographers, as learners, would "artfully engage with their surroundings to create impromptu sites of learning" (Sharples et al., 2007). In this case, we could conceivably equate research with learning due to both the compositional, narrative based nature of the representation as well as to the reflexive process of evaluation.

In short, autoethnography remains a viable method particularly for technology-based explorations of open space, one that maintains a positioning of the individual as a reflexive practitioner, affected and affecting the larger environment, engaged in a series of digital, material, and hybrid relationships towards meaning making. Aesthetic literacy attempts to distil all these positions into one method. It is important to note that this approach routinely complicates the boundaries between teaching and research in that it presupposes that exploration of this sort is inherently both a learning and research activity. Autoethnography, as a method embedded with reflexive practice, is, in and of itself, a learning activity. Aesthetic literacy, defined in the following section, is a method for efficiently employing autoethnography in open learning settings.

\section{Applied Context: Helsinki, Finland (2013) and Tallinn, Estonia (2013)}

The structure of aesthetic literacy and the activities used to stimulate its development as detailed in the following sections of this paper were predicated on experiences from two formal workshops conducted by the authors in Helsinki, Finland (2013) and Tallinn, Estonia (2013).

The first of these activities to be conducted, the Helsinki event was a two-day workshop conducted with teachers and researchers (Otavan Opisto) in May, 2013. The workshop was intended to explore mobile learning and the field activities for use in, or as supplement to, formal learning activity. Participants were asked to explore the urban space of Helsinki through a disciplinary lens: historical, architectural, pedagogical, religious, etc. They were asked to reflect on their selections of topic, of technology, of modes and composition, and the quality of the data collected. They were asked to avoid developing a rigid process or focus ahead of the actual urban exploration and data collection.

Day 1 of the workshop began with discussion on mobile learning as a transformation of habitus (adapted from Kress \& Pachler, 2007), or as a transformation of the urban space into learning space. Participants grouped themselves around thematic interests, discussed possible urban spaces of interest to that theme, pooled technology to ensure a broad range of collected data, and 
struck out into Helsinki to explore, discuss, collect, and analyze, without a rigid itinerary, the urban space. After collecting the data, participants returned home. Day 2 of the workshop involved appraising the data collected, reflecting on the processes used to collect that data and composing the data into an artifact to be presented to the larger group. There were no restrictions of any sort placed on the data collected, the technology used to collect or compose that data, or the presentation mechanism. Participants were simply asked to present the meaning they acquired in the way that made sense to them. The four groups produced artifacts ranging from collages of audio, video, and imagery, to sound maps of the Helsinki Tram system, to more philosophical explorations of habitus (via Kress \& Pachler, 2007), to further explorations of architecture and religion via the Helsinki urban landscape. Two of these are presented below.

\section{Group 3: Helsinki Tram Sound Map}

This group chose to capture the sounds of the tram that ran from downtown Helsinki (the site of the workshop) to their respective homes at the end of the tramline (approximately 30 minutes away). They recorded audio at three different stations, alighting at these stations to record audio without imagery. This was coupled with another 30-60 seconds of one of the participants who had closed their eyes describing what they had heard at various stations on the tram line. They also presented imagery as well to represent the location and reconstituted this composition on an interactive map via Prezi (a presentation tool found at https://prezi.com).

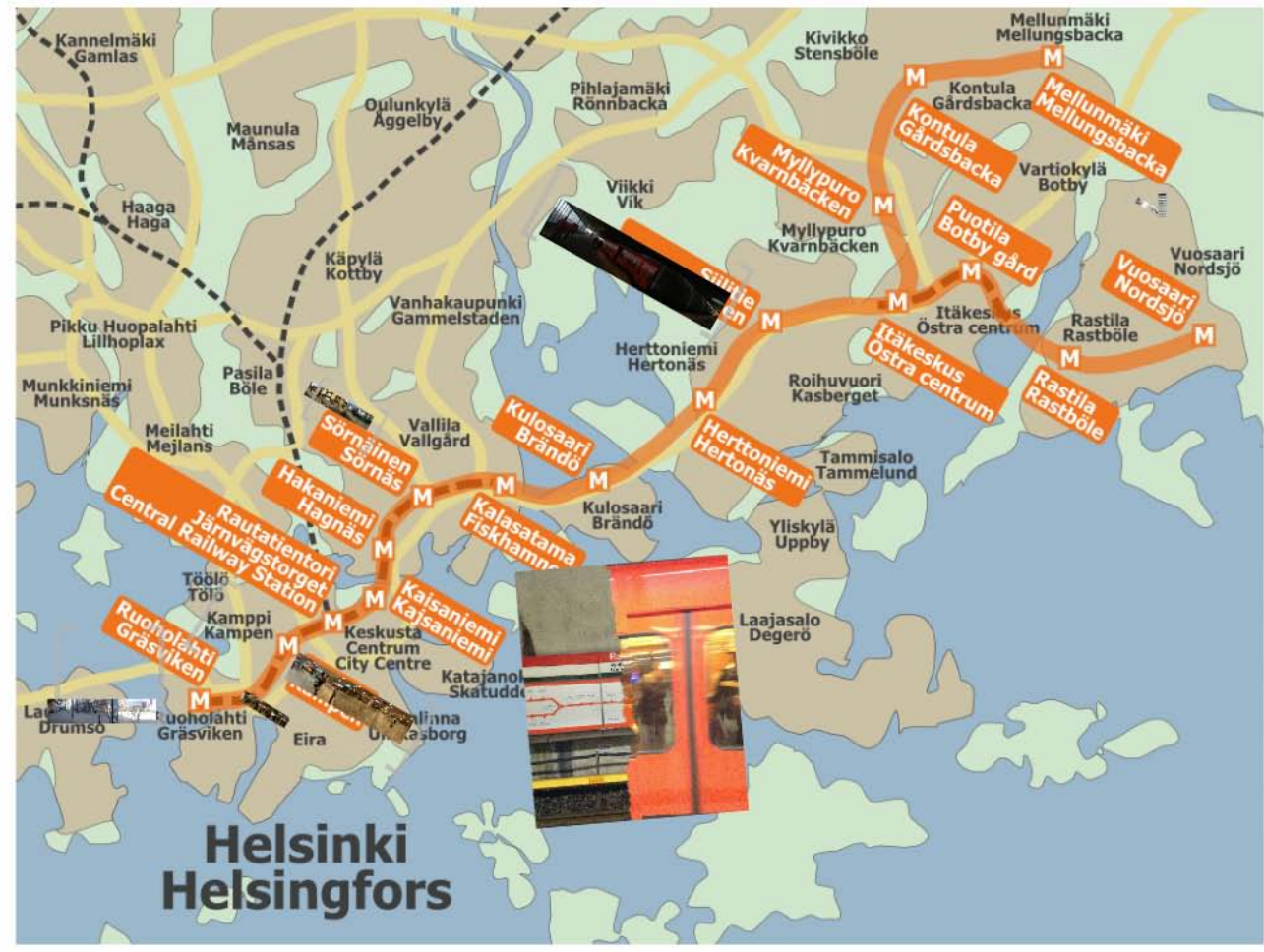

Figure 1. Helsinki Aural Tram Map

\section{Group 4: Habitus}

This group set out to discover, via a combination of ethnography (observing others) and autoethnography (observing themselves observing others) whether they could observe the transformation of habitus in mobile learners, to make it visible in practice. So the objective was to scour the parks of downtown Helsinki to observe how people used their mobile technologies to make sense of their surroundings. This quickly evolved into an exploration of how mobile technology had changed social practice, how people interacted with each other and their world. 
These participants began to realize they themselves were the subject of transformation. They spent time collecting imagery, observed and articulated how the young people in the parks weren't using mobile technology when with their friends, only when seemingly isolated. In short, they observed that using mobile technology was a lifeline/connection to a larger sphere of social activity. This group in particular, bound less by linear geography as compared to the first group composing the Helsinki tram system, adopted a flanerie (outlined in Shields, 1994) as their approach, steadfastly refusing to plan an itinerary before heading into Helsinki.

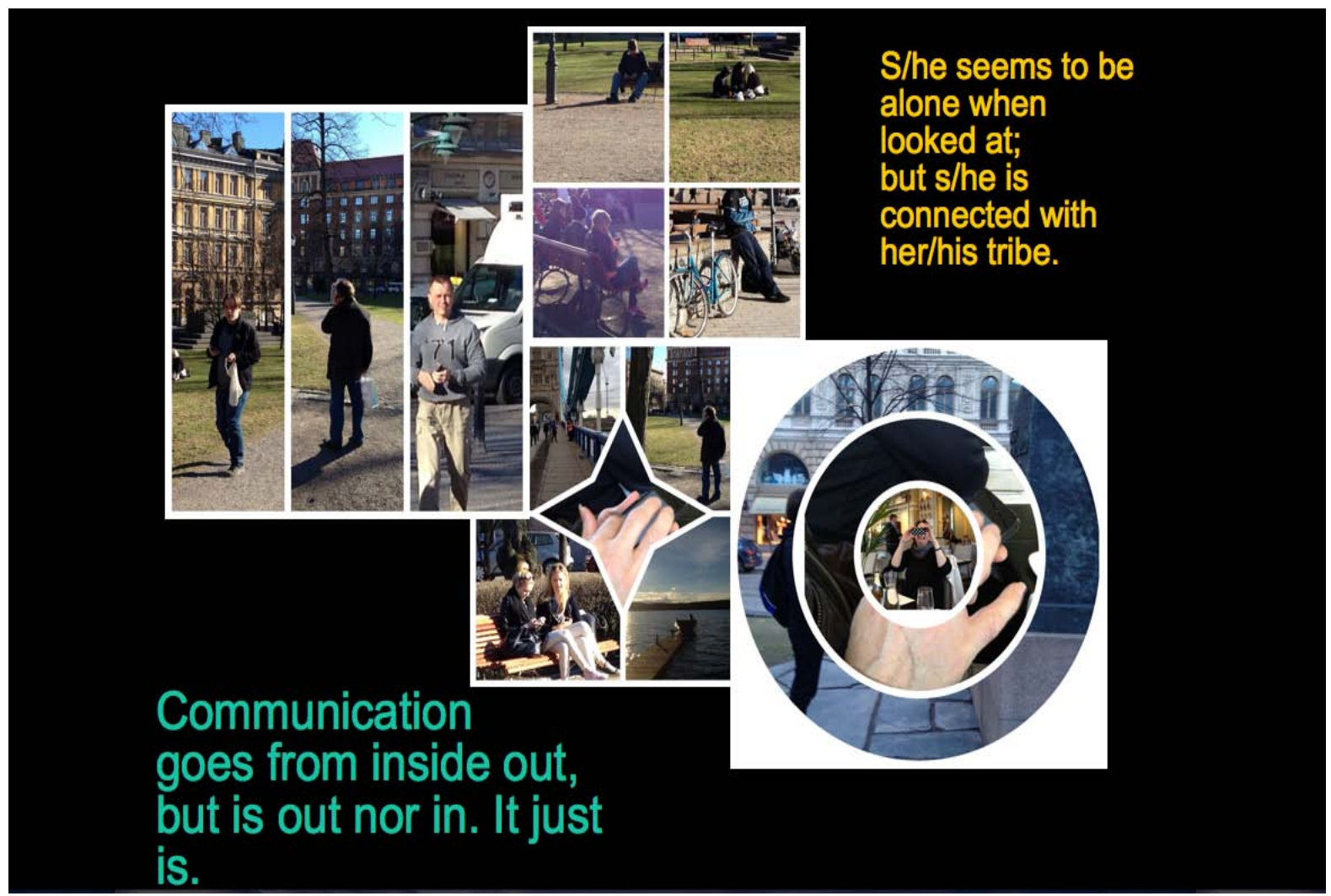

Figure 2. Collage of habitus transformation from Helsinki workshop

In keeping with autoethnography as both ethnography and autobiography, the author remixed these compositions from these groups along with video shot on the way to the airport as an initial reflection on the workshop, into the practices and compositions generated as a result of the workshop, and the role of autoethnography as a viable means of engaging open learning in urban spaces (Gallagher, 2013). The participants and the author exhibited extensive reflexive practice in their chosen geographies, their data collected, and the compositions emerging from that data. They did not preselect the geography or the granular activities comprising the learning, but rather allowed the learning to emerge from the serendipitous engagement with the open urban space.

\section{Findings emerging from the workshops: Toward a pedagogy}

What these workshops suggested was the need for developing capacity for learning in open spaces (such as Helsinki and Tallinn), spaces without predefined learning objectives, curricula, or outcomes. Learners in these spaces confront the open space and glean meaning from parameters defined and articulated by themselves. Learning is reflected on and appraised; learning processes are iterated upon and augmented or discarded. Motivation and maturity present themselves as mitigating factors in this process. Yet, these workshops suggested the viability of employing mobile learning as a vehicle for activating lifelong learning, a process discussed in Beetham \& Sharpe (2013) in regards to designing learning and redefining pedagogy in open spaces, and in 
Seta et al (2014) in relation specifically to mLLL (mobile lifelong learning). As such, the research presented in this paper builds on these explorations of appropriate pedagogy and frameworks for initiating lifelong learning in mobile and open spaces. What differentiates the research presented here from other work is our emphasis on personal capacity for identifying and articulating the learning potential for open spaces, a process that can be entirely devoid of technology. We believe lifelong learners must develop capacity for what we refer to as aesthetic literacy as a precursor to all lifelong learning that might take place in mobile, open spaces. In short, the learners from these workshops were forced to not only learn in open spaces, but also to first learn how to learn. We liken this learning how to learn to aesthetic literacy.

How do we learn in open spaces? How do we make open spaces learning spaces? How do we activate or stimulate that learning in students? Aesthetic literacy is one method for doing so, one we believe holds much promise for open and lifelong learning. The world and realities we live in are in a continual state of emergence. They are difficult to decipher in their ephemeral composition-overlap and intricacy; they are permeated by human presence and non-presence (experienced absences) (Gallagher \& Ihanainen, 2014a). Open space is composed of simultaneous spatial, temporal and social presence practices (Farman, 2012). We believe this complexity is best activated for learning through an appropriate pedagogy, one that can make this "messy system" an approachable and useful learning space. Aesthetic literacy as learning method meets these contemporary demands mentioned above.

Aesthetic literacy pedagogically sees learning taking place in perceiving and acting gliding all the time into each other. The learning, in this sense, makes itself true in perception-action environment becoming all along more subtle and wider in this multiple complexity. Aesthetic literacy is pedagogically based on ownership of personal sensing and acting; aesthetic literacy trusts in "selfies". It also gives space for authenticity of situations and events, which can be discussed into shared understandings on formal and informal forums. Finally, aesthetic literacy unfurls and enhances creativity to meet and experience hidden meaning in the ordinary. Aesthetic literacy helps pedagogically to grip and grasp the unclear and the vague, the insecure and incomplete, and things in movement.

\section{Making aesthetic literacy visible through activity}

Learning in this paper is positioned as a deliberate act balancing trust (in the learner to learn and in the environment to perceptually sensitive way stimulate that learning), behavioural rhetorics, activity (data collection, composition, socialized activity) and reflection (to identify what has been learned, what must be iterated upon, etc.). It is an intentional act of education, or "a process of living and not a preparation for future learning" (Dewey, 1938). This is a definition of learning which dovetails into the positioning of lifelong learning as consistent and self-regulated activity towards self-betterment and greater participation in society (Kurbanoglu, 2003). Learning in this context is generated, reflected on, and iterated through deliberate and consistent activity.

Making artifacts and compositions from this deliberate activity visible to the learner presents pedagogical advantages. First, the activity required to generate these artifacts or compositions (whether they be images, notes, videos, audio recordings, maps, etc.) is an act of aesthetic literacy, data collection, documentation, and, subsequently, an act of memory. Learners train themselves through deliberate activity to take a photograph, for example, in each new environment they encounter over the course of the day, or at regular intervals throughout the day. This consistent activity makes visible the process of aesthetic literacy through documentation; the learner develops aesthetic literacy by acknowledging the environment is new, and begins to transform space into learning space (Kress \& Pachler, 2007) through the act of documentation. 
Learners accumulate artifacts in this way and begin to assemble them into compositions at consistent intervals (time interval or after an accumulation of a certain amount of artifacts, etc.). These compositions are designed, in these early stages divorced from formal assessment, to be mere aggregations of meaning. This image assembled with this video and these audio recordings, etc. In this way, learners are composing their ephemeral learning environments and their own learning identities through consistent activity by slotting these artifacts into compositions and these compositions into narratives. Narratives in this instance are sequences of activities and compositions presenting intentional state entailment (Bruner, 1991), a deliberate presentation of their own sense of understanding in a particular environment. A learner might aggregate video, audio, imagery and text into one composition and reflect, consciously and deliberately, on what it is presenting and how that presentation reflects their evolving identity as a lifelong learner, their understanding of the environment and its capacity for generating meaning, and their knowledge gaps within this environment. Deliberate activity and reflection assists in constructing intentional state entailment; these learners are forging narratives of aggressive intentionality through consistent activity. These narratives are intentional in their present representation and in their future projection. Learners are deliberately attempting to represent what has been learned to date, while at the same time willing into existence all they hope to learn. As such, narratives are reflective markers of great significance in charting a learning trajectory (Wenger, 1998). Unlike Wenger's focus on community membership, however, we expect learners to use these narratives not as tool for community engagement, but rather as tool of reflection and self-regulation.

This reflection on individual compositions can then be broadened to reflection on practices and processes in which this learning takes place. Learners can begin to iterate on the structure of activity overall, the multimodal affordances of each media being used (image over video, for example), their assembled significance (as compositions) and the intervals in which this activity is being performed. They can adjust workflows and augment reflective practices. This reflective practice towards process iteration is critical to self-regulation and therefore to lifelong learning overall. This can be made visible to the learner only through deliberate and consistent activity and reflection, cultivated as such. The teacher in this space has considerable capacity for 'training' learners to enact these practices consciously and deliberately, to make visible aesthetic literacy and subsequent learning practices.

\section{Pedagogical Activity}

The activity that can be presented to transform space into learning space, to generate aesthetic literacy, and to provide learners with capacity for self-regulating their own learning, is most easily presented through representative categories. It should be noted that many of these activities are technological in nature, which broaches mobile lifelong learning (mLLL) as presented earlier in this paper. Mobile technology presents the most readily accessible (broadly) for engaging many of these activities; as such, it should be considered as a potential learning tool to be engaged with throughout this process. However, mobile technology, possibly due to its sheer ubiquity, comes with it many socio-cultural practices of use and production, practices specific to the context in which this mobile technology has been employed. It adopts and often hybridizes existing social norms for interaction. It generates media practices that incorporate any number of community norms and memberships (harkening back to Wenger, 1998). These need to be considered and reflected on by the teacher and the learner before embarking on the activities presented below.

\section{Beauty adjusted: cultivating aesthetic literacy}

Aesthetic literacy commands great importance in this presentation of learning as an act of constant activity and iteration. Aesthetic literacy is the act of transforming space into learning space. It is a mix of perception, intellect, and emotion, an understanding that all environments are pregnant with the possibility of learning if we adjust ourselves towards receiving it. Making the 
process of alignment and attunement visible is done primarily through documentation and data collection. Learners can perform any number of activities when presented with a new or evolving environment, including the following:

- Taking a photograph or video of "newness": at regular intervals or whenever presented with a new or evolving environment, the learner documents the space through a photograph. This simple act of documentation embeds the artifact in the memory, and the memory potentially to the narrative. It documents aesthetic literacy by acknowledging that the first stages of alignment and attunement have been performed and the space transformed into learning space.

- Taking a photograph or video in a particular location at a consistent time: in this exercise, the evolution of the space becomes the object of focus. The learner develops an understanding of the space as perpetually evolving, suggesting that the learner's understanding of the space is perpetually evolving as well. It is an act of elongated aesthetic literacy in that alignment and attunement are taking place over a course of time and indefinitely.

- Taking an audio recording: non-voice acts, i.e. ambient audio, are under-theorized artifacts of cognitive activity, but useful for aesthetic literacy in that they are received, or waded through, rather than presented. An example would be a pristine image of an urban scene, presenting stillness and sanctuary, positioned against an audio recording of a screeching tire or a car horn.

- Soundtracking space: in this activity, learners are asked to orient themselves to open space by creating soundtracks or sound surveys of particular locations. This is a method appropriated from research on the role of music in academic and online study (Elektronisches Lernen Muzik, 2014), as well as sound surveys documenting the aural landscape of a particular urban environment (London Sound Survey, 2014). Learners create soundtracks to generate an aesthetic literacy in unfamiliar spaces or spaces that are to be transformed into learning spaces through deliberate activity.

\section{Data Collection and Composition}

Many of the activities listed above were indeed data collection activities. Data collection is of critical important to field activity (as described in detail in Gallagher \& Ihanainen, 2014a; Gallagher, 2013). Data collection is more than documentation, however. It is the identification of material of possible relevance for later composition. It is important to acknowledge this possibility; significance is not pre-ordained nor is always apparent before documentation. The documentation and data collection itself, a deliberate act of learning, will often generate the significance. It is important for the learner in managing their own lifelong learning as it is material through which learning activity will take place, the artifacts of their learning practices. As such, it is important to make it known to the learner that the production of such material at consistent intervals is an important practice in their overall learning process. It is the material that will be used and reused to generate meaning through composition and reflection.

Activities that collect data are numerous, many of which can extend into more formal disciplinary based learning. Historical documentation of a particular location, a neighbourhood, a street, etc. can provide data that will be used to advance a disciplinary understanding. Consistent recording of audio to map the sound quality of a particular neighbourhood or informal interviews to record the narratives of those who live there, video to document traffic down a particular street or patterns of activity, photographs to document impressions of sunsets or changing weather patterns. Consistent data collection is the cultivating of the inquisitive learner. It is enacting the expectation of learning everywhere at anytime. 
Composition is broadly defined here as any aggregation, or 'writing', of material to present meaning (likened to narrative inquiry via Webster \& Mertova, 2007). Its practices are numerous as are its possible presentations or containers. If we are dealing with the materials of data collection, primarily if not exclusively digital, then this involves the composing of video, audio, imagery, text, and other modes of meaning into larger aggregates. Some examples of this activity might include:

- Field Notes, Blogging-primarily a textual medium, but one that can be enacted verbally (voice recordings or dictations) or through other multimedia (through images, audio, or video). This type of activity is both composition and reflection, a persistent presentation and iteration of both learning and self in relation to that learning.

- Montages, collages, mash-ups: these are simple aggregations of media for a particular effect or representation, ones that can be composed in smart mobile technology through commercial applications. These multimodal compositions present opportunities for reflection around the applicability of the media to the particular medium, how these forms of media are assembled and arranged, etc. (Multimodality provides a useful basis to inform these reflections; see Jewitt (2009) for a broad treatment of multimodality).

- Mapping: whether digital or hand-drawn are compositions of the construction of geographical and cognitive space. Learners engage in aesthetic literacy to transform space and compose space into larger aggregations through mapping. It is the composition of space itself and, in turn, the learner's identity within that space that is being reflected on.

- Geocaching: allowing the learners to compose caches of geo-positioned material for gaming and learning purposes has been discussed extensively in research, particularly in respect towards embodiment (Farman, 2009). Embodiment has significant pedagogical value in that it forces a reflection on the role of space and the learner's position within it, essentially a reflection of aesthetic literacy itself. Learners compose caches of material, whether media, text, coordinates, material objects, etc., geolocate those caches, and spend time finding and adding to found caches from other learners. What these caches reveal, among other things, is the composition of aesthetic literacy, or the process by which space is transformed into learning space through alignment and attunement. A geocache is a composition reflecting on that learning space, and the narrative of the learner's relationship to it.

\section{Reflection}

Reflective practice is of great importance to several of the processes and fields described in this paper, including lifelong learning, self-regulation, and aesthetic literacy. It is generally enacted through composition, often as a formal writing prompt or assessable activity. Reflection as it relates to aesthetic literacy can be enacted through these methods, but others exist (as outlined convincingly in Byrne \& Jones, 2009). Pedagogically, it is important to maintain instructional focus on the process over the output in terms of choosing suitable reflective practices.

These questions are primarily directed at the teacher, but a self-regulated learner will need to consider them as well. Ultimately, the goal of these reflective prompts is to train the learner to consider these literacies on a consistent basis through the presentation of and prompting of visible phenomena. These reflections should be composed at consistent intervals to maintain an expected state of learning amidst the everyday and to maintain a constant process of iteration on these practices. Self-reflection of this sort is grounded in the work of Sengers et al. (2005) on reflective design, Verpoorten et al. (2012) on reflective triggers, and Ifenthaler's (2012) work on reflective prompts. These reflective activities or simple reflective prompts provide an opportunity for the participant to make conscious the learning, media, aesthetic, and compositional practices 
they currently employ to make meaning. The following activities are but some of the possible reflections that can be pedagogically cultivated by the teacher or by the learner themselves.

\section{Emotional and Intellectual Symmetry}

This category refers primarily to prompts provided by the teacher or the learner to themselves that seeks to identify the symmetry that exists between their intellectual activity and emotional receptiveness to that activity. A simple example would be a reflective prompt in the form of a question asking what has been accomplished, what remains to be accomplished, and how that satisfies the learner. Additional activities would seek to employ media to compose symmetry. The learner composes a 'postcard' at intervals (a method adapted from Bayne et al., 2014) from their learning, a collection of imagery, audio, and representative text that documents their satisfaction with their own learning. Positioning these compositions around "satisfaction", "progress", or "contentedness" forces the learner to bridge intellectual activity and emotional effect. Aesthetic literacy depends to some degree on the capacity of the learner to receive learning in unlikely places, and this process depends to some degree on the emotional context of alignment and attunement.

\section{Media Inventory and Review}

On the surface deceptively simple, this approach involves a review of media inventory generated through these activities at intervals. For example, the learner would review their imagery, their video, audio, and textual content, identify gaps in these inventories, and iterate on their processes. Media inventory review forces the learner to consider present learning efficacy (or self efficacy as defined, amongst other places, in Zimmermann, 2002). A media review at consistent intervals forces the learner to reflect on their capacity to meet their learning expectations based on the media, or learning material, they are generating. Media collection processes are iterated on as needed. The reflective practice of media review also initiates a reflection on narrative, or the ability of the learner to construct their own narrative of progress amidst the limitless possibility of open space, or lifelong learning.

\section{Pedagogical Advantages}

Pedagogically, it is important to consider the purpose of these activities in contributing to the reflective practices of learners interested in developing their own lifelong learning. Further, we need to identify the advantages in such activities and their underlying assumptions in relation to the lived world of the learner. What is to be gained with an emphasis on process over purpose, or a visualization of aesthetic literacy in our meaning-making environments? What is to be gained through an emphasis on what seems to be administrative or organizational activities (media inventory and review; process mapping and review) over formal outputs and assessments (essays, etc.)? The answers to these questions relate to the overall purpose of aesthetic literacy in orienting the learner towards reflective practice and process orientation. This, subsequently, is designed to stimulate learner self-efficacy and iterative practice, which actualizes lifelong learning. Lifelong learning, and the aesthetic literacy, activities, and positionings described in this paper, target specific skills as outlined by Kress (2009), skills that pedagogy has a responsibility to address:

1. The ability and skill to act flexibly in representation, communication, text-making and knowledge creation with a disposition to adaptability.

2. To understand principles of learning as the effect of sustained engagement by a learner with aspects of a learning environment, for instance through selection as framing and as transformation.

3. To have the skills and required disposition towards production with contemporary media in the creation of semiotic artefacts. 
4. To be at ease with real-time decision making...

The activities outlined in this paper attempt to address these skills pragmatically, through observable action, purposeful and consistent reflection, and iteration. The pedagogical advantages of such an approach charting aesthetic literacy through observable phenomena span the following groupings:

\section{Self-regulation and Iteration}

This pedagogical emphasis on aesthetic literacy is intended to create a self-regulatory system of learning, one where the individual learner is able to identify and iterate on existing learning practices based on the observable phenomena it produces. This definition of self-regulation can be likened to Bandura's notion of self-efficacy (1997), where one exercises control to achieve one's goals. However, in this context of developing and iterating on aesthetic literacy, self-control is linked to open iteration on existing practice. The learner develops aesthetic literacy pedagogically through constant experimentation, and through consistent reflection and iteration on practice based on the feedback received through observable phenomena. An example of this might be a learner generating a learning activity in a public square in an urban setting (for example, a chalk drawing on the pavement). Learners align and attune themselves to the potential of learning in this environment, collecting and composing data as a result, and iterates on this process based on the feedback received from the composition. Adjustments are made to the learning practices in an iterative cycle of activity and reflection.

\section{Cultivating the Capacity for Consistent (\& Lifelong) Learning}

Complementary to the self-regulation of learning based on consistent feedback is the notion of cultivating oneself to actively seek learning in the "rhythms of the everyday" (Lankshear \& Knobel, 2011), or the open environments of everyday life. Cultivation in this instance is a state of consistent anticipation, or a persistent expectation of learning amidst our everyday lives. "Everyday practices" emerge from this consistent learning engagement with our open environments, but we must first cultivate ourselves to actively expect and seek learning in open space. The pedagogical approaches outlined in this paper attempt to present aesthetic literacy as a means of cultivating ourselves to expect learning in the everyday by making visible the stages of alignment and attunement. It is important to note that this is a conscious process, a reflective practice of engaging with the visible phenomena. Learners in this space are encouraged to reflect often and openly about the role of these practices in their learning, and how it inhibits or develops their capacity for self-regulation. The focus here is not on understanding intelligence, but in generating intelligent action through the reflective development of aesthetic literacy. This is done through cultivating oneself to expect, to generate, and to receive learning in open space.

\section{Ownership of learning}

Aesthetic literacy strengthens one's self-regulation and capacity for orienting aesthetically with her/his environments. The self-regulation connected with orientation mean together enhancing consciousness and activity to own one's actual and ongoing setting in (social) situations, and especially ownership of learning in them. Aesthetic literacy goes against authored and outcomedriven learning and gives space and develops the ownership of learning. Whenever an open space is transformed into a learning space (engineered through aesthetic literacy), it demonstrates an emerging ownership of learning. This ownership of learning suggests self-regulation of learning, a critical component of a successful lifelong learner. 


\section{Generating a Process Orientation}

The process of making aesthetic literacy visible has a direct emphasis on a process over output orientation. By extending reflective practice to these earlier stages of learning (alignment and attunement), learners begin to reflect on the role they have in making use of open environments for learning, and the role they have in generating subsequent learning effort (composition, reflection, dissemination). Learners invest in these earlier stages as a means of generating the later ones.

Such a process emphasis also reveals a great connection between the stages of learning to the learner. The learner becomes aware of the necessity of alignment and attunement before questions can be put to this transformed open environment; the learner becomes aware, in turn, of the possibility of transforming every open environment into a learning one. This approach does not account for motivation or intent; it is possible to be aware of the value of alignment and attunement in the larger process of coming to know without having the discipline to cultivate oneself to make use of it. However, we believe that by making these earlier stages visible through consistent activity and reflection, a greater number of learners will orient themselves towards a more aggressive approach to their own learning. They will make use of open space if the emphasis on output is lessened, or at least juxtaposed against that of process.

\section{Linking Pedagogy to Lifelong Learning}

The pedagogical activities described in this paper attempt to position lifelong learning as a process orientation, one that begins with aesthetic literacy and carries through to composition, iteration, and reflection. The activities listed in this paper also attempt to cultivate capacity for lifelong learning through what can be best described as exercise, a process of consistent activity designed to make visible the perceptual phenomena that accompany aesthetic literacy. This approach to lifelong learning is specifically designed to be learner-centred, as the primary goal is to develop learners able to be self-regulating in their learning. This approach is also designed to make use of open environments, the daily milieu of everyday experience, for learning through aesthetic literacy. It is open learning broadly defined, an openness referring to the expanse of space in one's lived environment rather than the form or structure (open course, open source, open learning as discussed in Ihanainen \& Gallagher, 2014).

It is also an approach that is in keeping with past research on lifelong learning and mobile technology; mobile technology has long been positioned as an ICT that is capable of cultivating the capacity for lifelong learning (Sharples, 2000). It is contestable to what degree this matching of mobile technology and lifelong learning, most notably through mobile lifelong learning (mLLL), has been successful as a national or regional effort (as defined by the European Commission in the Memorandum of Lifelong Learning (2000). However, much research has been generated identifying learning approaches appropriate to the use of mobile technology for lifelong learning (outlined in Holzinger et al., 2005; Nordin et al., 2010); this paper is designed to extend this conversation to include a process orientation to learning, one that positions aesthetic literacy as an integral literacy for activating lifelong learning; further, not unlike physical exercise and its relationship to our overall physical health, this paper provides pedagogical activity that is designed to consistently and predictably cultivate lifelong learning. It is our belief that this aesthetic literacy can be 'taught' in the sense that its related observable phenomena can be made visible and a process put in place to make use of this observable phenomena for learning effect. This is done through the use of tools, mobile technology included, in a larger process of coming to know (Saljo, 1999). 


\section{Conclusion}

Aesthetic literacy is positioned in this paper as a desirable capacity for learning in the open spaces of the everyday, or in the "rhythms of the everyday" (Lankshear \& Knobel, 2011). This is learning that spans formal and informal learning, as well as socialized and individualized learning (adapted from Park, 2011); it provides a means for validating formal, disciplinary learning in informal spaces through the learning process and suggested activities of aesthetic literacy, composition, iteration, and reflection described in this paper. It provides a means for creating self-regulating learners capable of defining, testing, and adjusting their learning practices based on feedback receives. Most importantly, though, it provides a framework, or process, for learners to define knowledge gaps, design learning activities to address those knowledge gaps, iterate on process, and reflect on learning through consistent and predictable activity. As such, it remains relevant despite shifts in the broader environment of these learners; it can be adjusted based on feedback and reflection. It is a means of regulating learning itself rather than an output orientation, or a means by which learning is a consistent, active, and iterative.

Further research is needed to identify the socio-cultural practices (outlined in this paper as aesthetic processes) that might influence aesthetic literacy in particular environments, as well as the relationship between particular tools and the learning practices enacted there. There has been evidence to suggest that existing socio-cultural practices are incorporated, or re-traditionalized in hybrid form into tools, mobile technology in particular (as discussed in the Asian context in Yoon, 2003, 2006a, 2006b; Hjorth 2009, 2013); as such, it is important to understand the effects of these practices on the development of aesthetic literacy. Appropriate activities would need to be designed to reflect that socio-cultural orientation. Validation or assessment, if required, requires further research. As a learning orientation on process over output, it is problematic to assess any particular artifact from the learning process described in this paper as either summative or formative. These artifacts are the materials or tools of meaning-making but they are not the direct representations of learning. Further research is needed to determine if process iteration might serve as an appropriate focus for assessment.

The overriding focus of this paper is that aesthetic literacy is acquired through consistent activity, iteration, and reflection. It is therefore teachable in the sense that it can be pedagogically cultivated in the learner. It presents a means of activating lifelong learning, a means of providing the means for learners to regulate their own learning, and a means to do so through available tools, mobile technology included. Returning to the Memorandum of Lifelong Learning (2000), lifelong learning is "all learning activity undertaken through-out life, with the aim of improving knowledge, skills, and competence, within a personal, civic, social and/or employment-related respective"; we believe aesthetic literacy provides a means for the individual to begin to realize these aims.

\section{References}

1. Alheit, P. and Dausien, B. (2002). The 'double face' of lifelong learning: Two analytical perspectives on a' silent revolution'. In Studies in the Education of Adults, 34(1), (pp. 3-22).

2. Atkinson, P. and Hammersley, M. (1994). Ethnography and participant observation. Handbook of qualitative research. Thousand Oaks, CA: Sage.

3. Bandura, A. (1997). Self-efficacy: The exercise of control. New York: Freeman.

4. Bayne, S.; Gallagher, M.S. and Lamb, J. (2014). Being 'at' university: the social topologies of distance students. In Higher Education, 67(5), (pp. 569-583).

5. Beetham, H. and Sharpe, R. (eds.) (2013). Rethinking pedagogy for a digital age: Designing for 21st century learning. London: Routledge. 
6. Braet, A.C. (1992). Ethos, pathos and logos in Aristotle's Rhetoric: A re-examination. In Argumentation, 6(3), (pp. 307-320).

7. Bruner, J. (1991). The narrative construction of reality. In Critical inquiry, 18(1), (pp. 1-21).

8. Byrne, D. and Jones, G.J. (2009). Creating stories for reflection from multimodal lifelog content: an initial investigation. Designing for Reflection on Experience, Workshop at CHI 2009, Boston, MA, U.S.A., 2009.

9. Chang, C.H. and Ooi, G.L. (2008). Role of fieldwork in humanities and social studies education. What the West can learn from the East. Asian Perspectives on the Psychology of Learning and Motivation. In Research in Multicultural Education and International Perspectives Series, 7, (pp. 295-312).

10. Dewey, J. (1938). Experience and Education. New York: Collier Books.

11. Dörk, M.; Carpendale, S. and Williamson, C. (2011). The information flaneur: A fresh look at information seeking. In the Proceedings of the SIGCHI conference on buman factors in computing systems, (pp. 1215-1224). ACM, 2011, May.

12. Elektronisches Lernen Muzik (2014). Website. Retrieved August 30, 2014 from http://www.elernenmuzik.net

13. Ellis, C. and Bochner, A.P. (2000). Autoethnography, personal narrative, reflexivity. In N.K. Denzin \& Y.S. Lincoln (eds.), Handbook of qualitative research, (2nd ed.), (pp.733-768). Thousand Oaks, CA: Sage.

14. European Commission (2000). Memorandum on Lifelong Learning. Retrieved August, 10, 2014 from http://europa.eu/legislation_summaries/other/c11047_en.htm

15. Farman, J. (2009). Locative life: Geocaching, mobile gaming, and embodiment. In the Proceedings of the Digital Arts and Culture Conference - After Media: Embodiment and Context, University of California, Irvine, December 12-15, 2009, http://escholarship.org/uc/item/507938rr

16. Farman, J. (2012). Mobile interface theory: Embodied space and locative media. London: Routledge.

17. Farman, J. (ed.) (2013). The Mobile Story: Narrative Practices with Locative Technologies. London: Routledge.

18. Fejes, A. (2014). Lifelong learning and employability. In Challenging the European Area of Lifelong Learning', (pp. 99-107). Springer Netherlands.

19. Gale, R. (2005). Aesthetic literacy and the "living of lyrical moments". In Journal of Cognitive Affective Learning, 2(1), (pp. 1-9).

20. Gallagher, M. and Ihanainen, P. (2013). Pedagogy supporting the simultaneous learning processes of open education: Pedagogy of Simultaneity (PoS). Open Education 2030: Higher Education, European Commission, Joint Research Centre: Information Society Unit.

21. Gallagher, M. and Ihanainen, P. (2014a). Pedagogy of Simultaneity. Retrieved November, 2014 from http://www.pedagogyofsimultaneity.org

22. Gallagher, M. and Ihanainen, P. (2014b). Mobile Learning Field Activity: Pedagogy of Simultaneity to Support Learning. In the Open Networked Learning Conference 2014, Edinburgh.

23. Gallagher, M. (2013). Incessant Motion through Space: Mobile Learning Field Activities in the Humanities.

24. Gibbs, A. (1997). Focus groups. In Social research update, 19(8), (pp. 1-8). 
25. Hjorth, L. (2009). Mobile media in the Asia Pacific: gender and the art of being mobile. London: Taylor $\&$ Francis.

26. Hjorth, L. (2013). Locating the Visual: A Case Study of Gendered Location-Based Services and Camera Phone Practices in Seoul, South Korea. Television \& New Media.

27. Holzinger, A.; Nischelwitzer, A. and Meisenberger, M. (2005). Lifelong-learning support by m-learning: example scenarios. In eLearn, 2005(11), (p. 2).

28. Ifenthaler, D. (2012). Determining the effectiveness of prompts for self-regulated learning in problem-solving scenarios. In Journal of Educational Technology \& Society, 15(1), (pp. 38-52).

29. Ihanainen, P. (2013). Pedagogy of Simultaneity especially in a context of mobile learning. Pedagogy of Simultaneity workshop in Tallinn, Estonia. Retrieved December 10, 2014 from http://www.slideshare.net/pekkai/pedagogy-of-simultaneitytallinn2013

30. Ihanainen, P. and Gallagher, M. (2014). Learning in the Open. Futura, Finnish Society for Future Studies.

31. Järvilehto, T. (2000). Feeling as knowing: 1. Emotions a reorganization of the organism environment system. In Consciousness and Emotion, 1(2), (pp. 53-65).

32. Järvilehto, T.; Nurkkala, V.-M.; Koskela, K. and Kalermo, J. (2013). Anticipation as a Main Principle of Neural Function and Mastering of Driving. In Dorn \& Sullman (eds.), Driver Behaviour and Training, Vol VI. Retrieved August 27, 2014 from_http://cse.fi/en/wpcontent/uploads/2014/03/Anticipation-and-driving-skill-final.pdf

33. Jewitt, C. (ed.) (2009). The Routledge Handbook of Multimodal Analysis. London: Routledge.

34. Kalz, M. (2014). Lifelong Learning and its support with new technologies. In N.J. Smelser \& P.B. Baltes (eds.), International Encyclopedia of the Social and Behavioral Sciences. Oxford, United Kingdom: Pergamon. Retrieved August 25, 2014 from http://dspace.learningnetworks.org/handle/1820/5321

35. Koper, R. and Tattersall, C. (2004). New directions for lifelong learning using network technologies. In British Journal of Educational Technology, 35(6), (pp. 689-700). DOI: 10.1111/j.1467-8535.2004.00427.x

36. Kress, G. (2009). Multimodality: A social semiotic approach to contemporary communication. London: Routledge.

37. Kress, G. and Pachler, N. (eds.) (2007). Mobile Learning: Towards a Research Agenda. WLE Centre, Occasional Papers in Work-based Learning 1.

38. Kurbanoglu, S. (2003). Self-efficacy: a concept closely linked to information literacy and lifelong learning. In Journal of Documentation, 59(6), (pp. 635-646).

39. Lankshear, C. and Knobel, M. (2011). New Literacies: Everyday Practices And Social Learning: Everyday Practices and Social Learning. New York: McGraw-Hill International.

40. London Sound Survey (2014). Website. Retrieved August 30, 2014 from http://www.soundsurvey.org.uk

41. Nordin, N.; Embi, M.A. and Yunus, M.M. (2010). Mobile learning framework for lifelong learning. In Procedia-Social and Behavioral Sciences, 7, (pp. 130-138).

42. Park, Y. (2011). A pedagogical framework for mobile learning: Categorizing educational applications of mobile technologies into four types. In The International Review of Research in Open and Distance Learning, 12(2), (pp. 78-102). 
43. Saljo, R. (1999). Chapter: Learning as the use of tools. In K. Littleton \& P. Light (eds.), Learning with computers: Analysing productive interaction. London: Psychology Press.

44. Seta, L.; Kukulska-Hulme, A. and Arrigo, M. (2014). What have we learnt about mobile LifeLong Learning (mLLL)? In International Journal of Lifelong Education, 33(2), (pp.161-182).

45. Sengers, P.; Boehner, K.; David, S. and Kaye, J.J. (2005). Reflective design. In the Proceedings of the 4th decennial conference on Critical computing: between sense and sensibility, (pp. 49-58). ACM, 2005, August.

46. Sharples, M. (2000). The design of personal mobile technologies for lifelong learning. In Computers and Education, 34, (pp. 177-193).

47. Sharples, M.; Taylor, J. and Vavoula, G. (2007). A theory of learning for the mobile age. In R. Andrews \& C. Haythornthwaite (eds.), The Sage handbook of elearning research, (pp.221-47). London: Sage.

48. Shields, R. (1994). Fancy footwork: Walter Benjamin's notes on flânerie. Retrieved November 1, 2014 from https://www.zotero.org/jkalin/items/itemKey/2NEE5QU2

49. Tsakiris, D. (2014). Human Capital and Human Action in Lifelong Learning: Questions Concerning the Revival of a Seemingly Obvious Theory. In Challenging the European Area of Lifelong Learning', (pp. 109-119). Springer Netherlands.

50. Tuschling, A. and Engemann, C. (2006). From education to lifelong learning: The emerging regime of learning in the European Union. In Educational philosophy and theory, 38(4), (pp. 451469).

51. Verpoorten, D.; Westera, W. and Specht, M. (2012). Using reflection triggers while learning in an online course. In British Journal of Educational Technology, 43(6), (pp. 1030-1040).

52. Webster, L. and Mertova, P. (2007). Using narrative inquiry as a research method: An introduction to using critical event narrative analysis in research on learning and teaching. London: Routledge.

53. Wenger, E. (1998). Communities of Practice: Learning, Meaning and Identity. Boston: Cambridge University Press.

54. Yoon, K. (2003). Retraditionalizing the Mobile Young People's Sociality and Mobile Phone Use in Seoul, South Korea. In European Journal of Cultural Studies, 6(3), (pp. 327-343).

55. Yoon, K. (2006a). Local Sociality in Young People's Mobile Communications: A Korean case study. In Childhood, 13(2), (pp. 155-174).

56. Yoon, K. (2006b). The making of neo-Confucian cyberkids: representations of young mobile phone users in South Korea. In New Media \& Society, 8(5), (pp. 753-771).

57. Zimmermann, B.J. (2002). Becoming a self-regulated learner: An overview. In Theory into practice, 41(2), (pp. 64-70).

\section{Acknowledgement}

This work was supported by Hankuk University of Foreign Studies Research Fund of 2014. 